\title{
Isolation, Characterisation, Antibiotic Susceptibility and Molecular Profile of Enterotoxigenic Bacillus Cereus from Fried Soya Bean Cake (Awara)
}

\author{
Farida Ishaq, Yahaya Ocholi, Zakari Ladan \\ Department of Microbiology, Kaduna State University, Kaduna, Nigeria \\ Email address: \\ faridakauru@gmail.com (F. Ishaq) \\ To cite this article: \\ Farida Ishaq, Yahaya Ocholi, Zakari Ladan. Isolation, Characterisation, Antibiotic Susceptibility and Molecular Profile of Enterotoxigenic \\ Bacillus Cereus from Fried Soya Bean Cake (Awara). American Journal of BioScience. Vol. 6, No. 4, 2018, pp. 45-51. \\ doi: 10.11648/j.ajbio.20180604.11
}

Received: October 24, 2018; Accepted: November 22, 2018; Published: December 28, 2018

\begin{abstract}
A total of one hundred and fifty (150) "awara" samples were collected from different vendors in various parts of Kaduna metropolis and assessed for the presence of Bacillus spp. Three species of Bacillus (Bacillus cereus, Bacillus subtilis, and Bacillus licheniformis) were isolated on Mannitol Egg-yolk polymyxin Agar plates, characterized and identified from the "awara" samples by conventional method (Biochemical test). The occurrence of Bacillus cereus, Bacillus subtilis and Bacillus Licheniformis were 51 (34\%), 22 (14.7\%) and 13 (8.7\%). All the samples tested contained high number of Bacillus spp where Bacillus cereus had the highest number. Statistical analysis using P-Values indicated statistically significant difference $(\mathrm{P}=0.001)$ in Kawo and Tudun wada while there was no statistically significant difference in Unguwan dosa $(\mathrm{P}=0.341)$. Isolates were found to possess the hblD enterotoxin produced by Bacillus cereus. The enterotoxin producing Bacillus cereus isolates were found to be susceptible to Pefloxacin $(10 \mu \mathrm{g})$, Ciprofloxacin $(10 \mu \mathrm{g})$, Streptomycin $(10 \mu \mathrm{g})$, Septrin $(30 \mu \mathrm{g})$ and Erythromycin $(10 \mu \mathrm{g})$. Resistance was observed against Ampiclox $(30 \mu \mathrm{g})$ while Gentamycin, $(10 \mu \mathrm{g})$, Zinnacef $(20 \mu \mathrm{g})$, Amoxacillin $(30 \mu \mathrm{g})$ and Rocephin $(25 \mu \mathrm{g})$ were found to be less susceptible respectively. All the "awara" samples were highly contaminated with $B$. cereus probably because its spores were very difficult to be eliminated from food materials by heat treatment. However, any outbreak can be effectively treated using the antibiotics that showed susceptibility.
\end{abstract}

Keywords: Bacillus cereus, Enterotoxin, Antibacterial Susceptibility, Multiple Antibiotic Resistance (MAR) Index

\section{Introduction}

Bacillus cereus is a Gram-positive, spore-forming microorganism capable of causing foodborne disease. At present three enterotoxins, able to cause the diarrheal syndrome, have been described: hemolysin BL (HBL), nonhemolytic enterotoxin (NHE) and cytotoxin K. HBL and NHE are othree-component proteins, whereas cytotoxin $\mathrm{K}$ is a single protein toxin. Symptoms caused by the latter toxin are more severe and may even involve necrosis. In general, the onset of symptoms is within 6 to $24 \mathrm{~h}$ after consumption of the incriminated food. $B$. cereus food poisoning is underestimated probably because of the short duration of the illness ( 24 h) [30].

In 1887 , Bacillus cereus isolated from air in a cowshed by Frankland and Frankland [11]. Since 1950, many outbreaks from a variety of foods including meat and vegetable soups, cooked meat and poultry, fish, milk and ice cream were described in Europe. In 1969, the first well-characterized Bacillus cereus outbreak in the USA was documented. Since 1971, a number of B. cereus poisonings of a different type, called the vomiting type, were reported. This type of poisoning was characterized by an acute attack of nausea and vomiting $1-5 \mathrm{~h}$ after consumption of the incriminated meal. Sometimes, the incubation time was as short as 15-30 min or as long as $6-12 \mathrm{~h}$. almost all the vomiting type outbreaks were associated with consumption of cooked rice. This type of poisoning resembled staphylococcal food poisoning [13].

The genus Bacillus is very diverse; it is presently divided into six subgroups based on spore morphology. B. cereus falls in the Bacillus subtilis group, and it is closely related to B. anthracis, B. mycoides and B. thuringiensis. Some argue, 
because of the close relatedness, that the three later species should be classified as sub-species of $B$. cereus. B. cereus and $B$. anthracis are both recognized as pathogens, but the former is implicated with foodborne disease. B. anthracis can infect perorally, but is inefficient [38].

$B$. cereus is ubiquitous in nature. It is believed that the primary habitat of $B$. cereus is soil. It is found rather frequently in foods such as meats, poultry, milk, cereals, starches, herbs, and spices. Foods implicated with the diarrheal type of $B$. cereus poisoning include milk, vegetables, meat, and fish. Foods associated with the emetic type of poisoning include rice products, potato, pasta, and cheese products. Other foods such as sauces, pastries, soups, puddings, and salads were identified as vehicles in food poisoning outbreaks [13].

\section{Materials and Methods}

Glass ware: All glass wares used are thoroughly cleaned with ethanol and rinsed with distilled water before use.

\subsection{Sampling Site and Collection}

Samples of awara were purchased from three (3) locations namely: Kawo, Tudun wada and Unguwan dosa from the production points and hawkers at each part of the sampling area within Kaduna metropolis in a clean polythene bag (50 from each location), and were immediately transported to Food and Industrial Microbiology research laboratory of the Department of Microbiology, Kaduna State University.

\subsection{Preparation of Mannitol Egg-Yolk Polymyxin Agar (MYP)}

Exactly $21.5 \mathrm{~g}$ of the mannitol egg-yolk polymyxin agar base was suspended in $450 \mathrm{ml}$ of distilled water; it was mixed well and dissolved by heating with frequent agitation. The medium was then boiled for one minute until complete dissolution. Sterilization in autoclave was done at $121^{\circ} \mathrm{C}$ for 15 minutes. The medium was then allowed cool to $45-50^{\circ} \mathrm{C}$, after which one vial of polymyxin-B supplement and eggyolk suspension were added, mixed well and then dispensed into sterile petri dishes. The prepared medium was stored at $8-15^{\circ} \mathrm{C}$ for use during cultivation [15].

\subsection{Enumeration and Identification of Bacillus Cereus}

Stock samples of awara were prepared by weighing and blending $25 \mathrm{~g}$ of each "awara" in $225 \mathrm{ml}$ of sterile $0.1 \%$ buffered peptone water. The homogenate were subjected to ten-fold serial dilutions by transferring $1 \mathrm{ml}$ of the homogenate into $9 \mathrm{ml}$ of sterile $0.1 \%$ buffered peptone water. From this serial dilution, $1 \mathrm{ml}$ of $10^{-5}, 10^{-6}$ and $10^{-7}$ dilutions were plated on freshly prepared mannitol Egg-Yolk polymyxin agar (MYP), a highly selective medium for Bacillus cereus developed by Holbrook and Anderson, 1980 [15]. The inoculated agar plates were incubated at $37^{\circ} \mathrm{C}$ for $24 \mathrm{hrs}$. The isolates were examined for growth and all samples showed growth within $24 \mathrm{hrs}$ of incubation. Colonies that appeared pink, surrounded by whitish zones of clearance were presumed to be $B$. cereus. Colonies that appeared yellow were presumed to be $B$. subtilis, those that appeared creamy were presumed to be $B$. licheniformis. Colonies of Bacillus cereus grown on MYP are pink and lecithinase positive, but other bacteria are not inhibited and can interfere with isolation of Bacillus cereus [34]. The presumptive isolates were identified by morphological characteristics. The morphological test includes appearance of cell, shape and pigmentation. Further identification of the organisms using biochemical characteristics are Gram's reaction, position of spores, motility, oxidase, indole production, nitrate reduction, citrate, catalase, coagulase, methyl red voges proskaur and lecithinase [27]. The presumptive Bacillus cereus were confirmed using the PCR technique.

\subsection{Genomic DNA Extraction of the Bacterial Isolate}

High salt based method [38] was followed for genomic DNA extaction. Reagents used for genomic DNA extraction were TE buffer (Tris-EDTA), 10\% (w/v) sodium dodesyl sulfate (SDS), $20 \mathrm{mg} / \mathrm{ml}$ proteinase $\mathrm{K}, 5 \mathrm{M} \mathrm{NaCl}$, CTAB/NaCl solution, 24:1 chloroform/ isoamyl alcohol, 25:24:1 phenol/chloroform/isoamyl alcohol, isopropanol and $70 \%$ ethanol [23].

The tubes containing the cell pellet (approximately $500 \mu \mathrm{g}$ each test tube) were used for DNA extraction. The cell pellet was resuspended in $567 \mu 1 \mathrm{TE}$ buffer by repeated pipetting. $30 \mu 1$ of $10 \%$ SDS was added in all the tubes. However to observe the effect of different types of lysis agents on the overall extraction procedure of Gram positive bacteria, lysis steps were carried out with 0,3 and $6 \mu$ l of proteinase- K respectively. For the entire step, DNA extraction was carried out in triplicate. $100 \mu \mathrm{l} 5 \mathrm{M} \mathrm{NaCl}$ was added and mixed thoroughly and $80 \mu \mathrm{CTAB} / \mathrm{NaCl}$.

Solutions were added to each tube and then the mass was mixed and incubated for $10 \mathrm{~min}$ at $65^{\circ} \mathrm{C}$. Equal volume chloroform/isoamyl alcohol was added, mixed and microcentrifuged (MIKRO 2, Hettich, Germany) at 13000 rpm for $4 \mathrm{~min}$. The supernatants were then transferred to a fresh tube, and $0.6 \mu \mathrm{l}$ of isopropanol was added and mixed gently and kept for 1 day at $-20^{\circ} \mathrm{C}$ for DNA precipitation. DNA pellets were then obtained by centrifuging at 13000 rpm for 4 minute, and then dried and resuspended in $100 \mu 1$ TE buffer [23].

\subsection{PCR Assay of Genomic DNA Using HBLD (Primer) and Gel Electrophoresis}

The DNA extracts and controls were amplified with primers, 200mM of each dNTP (Promega), $10 \mathrm{mM} \mathrm{KCl} \mathrm{PCR}$ buffer, $2 \mathrm{mM} \mathrm{MgCl}_{2}$ and $1.0 \mathrm{U}$ Taq polymerase (Bioline). Amplification conditions for the PCR were as follows: $5 \mathrm{~min}$ at $94^{\circ} \mathrm{C}$ to denature the DNA, followed by 40 cycles of denaturation at $94^{\circ} \mathrm{C}$ for $1 \mathrm{~min}$, primer annealing at $55^{\circ} \mathrm{C}$ for $1 \mathrm{~min}$ and strand extension at $72^{\circ} \mathrm{C}$ for $2 \min$ on a programmable thermal controller. The amplified PCR products were separated by electrophoresis on a $1.5 \%$ 
agarose gel with $0.5 \%$ ethidium bromide in 1 xTAE buffer and DNA ladder were visualized under ultraviolet (UV) light photographed by Gel Doc 2000 [4].

\subsection{Antibiotic Susceptibility}

Bacillus cereus isolates were tested for their sensitivity to antibiotics by means of disc diffusion method [29]. The organisms were investigated using antibiotic disc containing: Pefloxacin $(10 \mu \mathrm{g})$, Gentamycin $(10 \mu \mathrm{g})$ Ampiclox $(30 \mu \mathrm{g})$ Zinnacef $(20 \mu \mathrm{g})$, Amoxacilin $(30 \mu \mathrm{g})$, Rocephin $(25 \mu \mathrm{g})$, Ciprofloxacin $(10 \mu \mathrm{g})$, Streptomycin $(30 \mu \mathrm{g})$, Septrin $(30 \mu \mathrm{g})$, and Erythromycin $(10 \mu \mathrm{g})$. The antibiotic discs were spaciously placed on Mueller-Hinton agar plates previously seeded with overnight broth cultures of Bacillus cereus isolates. The plates were incubated at $37^{\circ} \mathrm{C}$ for $18-24$ hours. The plates were incubated at $37^{\circ} \mathrm{C}$ for $18-24$ hours. The different zones of inhibition were measured to the nearest millimetre and interpreted as sensitive (greater or equal to $18 \mathrm{~mm})$, moderate sensitive (13 to $17 \mathrm{~mm}$ ) and resistant (less than $13 \mathrm{~mm}$ ) based on the interpretation by Clinical Laboratory standard Institute (CLSI) [5, 6, 33].

\subsection{Multiple Antibiotic Resistant (MAR) Index}

The multiple antibiotic resistant (MAR) index was determined for the isolates by dividing the number of antibiotics to which the isolate is resistant by the total number of antibiotics tested [29].

$$
\text { MAR index }=\frac{\text { Number of antibiotics isolate is resistant to }}{\text { Total number of antibiotics tested }}
$$

\section{Results}

A total of one hundred and fifty (150) "awara" samples were purchased from various selling outlets in kaduna metropolis and were analysed, three species of Bacillus which include Bacillus cereus, Bacillus subtilis, and Bacillus licheniformis showed morphological appearance. All the Bacillus cereus isolated in the cause of this research revealed an irregular to round edge, flat, rough and dry bright pink colonies with zones of egg yolk precipitate on the selective agar (MYP) compared to other Bacillus spp identified. They are rod shaped and gram positive. Table 1.

Table 1. Cultural and Morphological Appearance of Bacillus Spp Isolated from Awara from Kawo, Tudun wada and Unguwan Dosa.

\begin{tabular}{llll}
\hline Number of samples & Colonial morphology & Cellular morphology & Gram's reaction \\
\hline 51 & pinkish colonies & Rods & Positive \\
22 & yellow colonies & Rods & Positive \\
13 & creamy colonies & Rods & Positive \\
\hline
\end{tabular}

The percentage (\%) ocurence of Bacillus spp isolates from the three sample areas showed that Bacillus cereus had the highest percentage $40 \%$, followed by Bacillus subtilis $16 \%$ and Bacillus licheniformis (6\%) from Kawo samples. This was closely followed by Tudun wada samples in which
Bacillus cereus had (38\%), followed by Bacillus subtilis (12\%), and Bacillus licheniformis (8\%), and lastly Unguwan dosa samples in which Bacillus cereus had (24\%), Bacillus subtilis (16\%), and Bacillus licheniformis (12\%) respectively.

Table 2. Percentage (\%) occurence of Bacillus spp Isolated from Awara from Kawo, Tudun wada and Unguwan dosa.

\begin{tabular}{llll}
\hline Sampling Area & $\begin{array}{l}\text { Number of samples Positive for } \\
\text { Bacillus cereus }\end{array}$ & $\begin{array}{l}\text { Number of sample positive for } \\
\text { Bacillus subtilis }\end{array}$ & $\begin{array}{l}\text { Number of sample positive for Bacillus } \\
\text { licheniformis }\end{array}$ \\
\hline Kawo & $20(40 \%)$ & $8(16 \%)$ & $3(6 \%)$ \\
Tudun Wada & $19(38 \%)$ & $6(12 \%)$ & $4(8 \%)$ \\
Ungwan Dosa & $12(24 \%)$ & $8(16 \%)$ & $6(12 \%)$ \\
Total & $51(34 \%)$ & $22(14.7 \%)$ & $13(8.7 \%)$ \\
Chi-Square Value & 4.471 & 0.727 & 2.154 \\
P-Values & 0.107 & 0.695 & 0.341 \\
\hline
\end{tabular}

Gel Electrophoresis of PCR Product of Bacillus cereus

The gel electrophoresis showed the band (Plate 1) obtained from PCR and the amplicon size is 829 base pairs, and primer used was hblD. Plate 1

Antibacterial Susceptibility Testing of the Enterotoxigenic Bacillus cereus
Table 3 showed the antibacterial susceptibility testing of the enterotoxin producing Bacillus cereus. The Bacillus cereus isolates were found to be susceptible to Pefloxacin, Ciprofloxacin, Streptomycin, Septrin and Erythromycin. Resistance was observed against Ampiclox while Gentamycin, Zinnacef, Amoxacilin and Rocephin were found to be less susceptible.

Table 3. Antibacterial Susceptibility testing of the Enterotoxigenic Bacillus cereus using 10 Commercially Available Antibiotics.

\begin{tabular}{llll}
\hline S/N & Antibiotics & Concentration & Categories \\
\hline 1 & Pefloxacin & $10 \mu \mathrm{g}$ & +++ \\
2 & Gentamycin & $10 \mu \mathrm{g}$ & ++ \\
3 & Ampiclox & $30 \mu \mathrm{g}$ & $+2 \mu \mathrm{g}$ \\
4 & Zinnacef & $30 \mu \mathrm{g}$ & - \\
5 & Amoxacilin & $25 \mu \mathrm{g}$ & ++ \\
6 & Rocephin & $10 \mu \mathrm{g}$ & ++ \\
7 & Ciprofloxacin & $30 \mu \mathrm{g}$ & ++ \\
8 & Streptomycin & +++ & +++ \\
\hline
\end{tabular}




\begin{tabular}{llll}
\hline $\mathbf{S} / \mathbf{N}$ & Antibiotics & Concentration & Categories \\
\hline 9 & Septrin & $30 \mu \mathrm{g}$ & +++ \\
10 & Erythmycin & $10 \mu \mathrm{g}$ & +++ \\
\hline
\end{tabular}

Key: $+++=$ Sensitive, $++=$ Moderate sensitive and $-=$ Resistance

Multiple Antibiotic Resistance (MAR) Index

MAR index $=\frac{\text { Number of antibiotics isolate is resistant to }}{\text { Total number of antibiotics tested }}$ $\mathrm{MAR}=\frac{1}{10}$ Therefore, $\mathrm{MAR}=0.1$

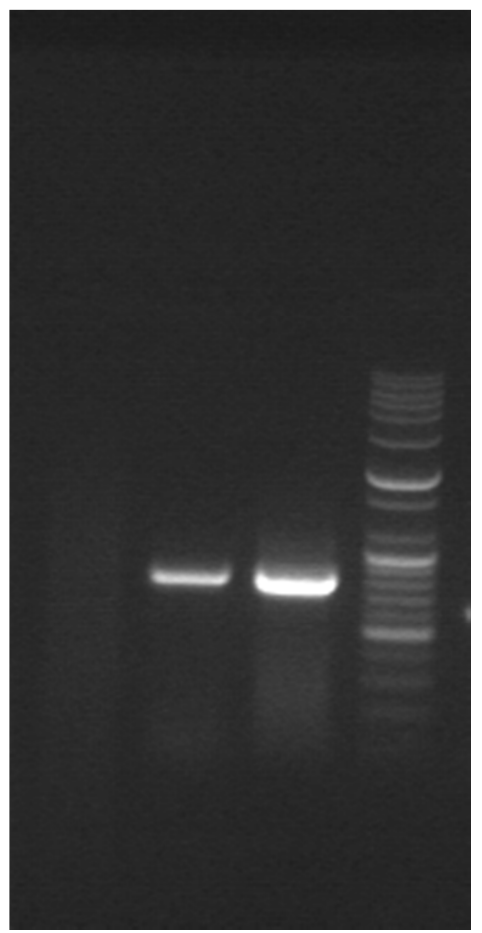

Figure 1. Gel electrophoresis of HBLD gene amplified by $P C R$, indicating the target DNA fragment was successfully amplified in the 2 samples. (Molecular weight marker, M 100 bp DNA ladder, lane 1 and 2, Bacillus cereus DNA.

\section{Discussion}

Bacillus cereus is becoming an important food poisoning organism because of its widely distribution in nature. Bacillus cereus could be transmitted to other foods when contaminated food products are used as constituents in the processing of these foods. The isolation of Bacillus cereus in all awara samples implies extreme contamination and potential health risk of these street food samples.

The cultural characteristics of the Bacillus spp isolated in this work (table 1) showed that Bacillus cereus appeared pinkish; Bacillus subtilis yellowish, while Bacillus licheniformis creamy. This correspond with the work of Okonlawon [24], who isolated Bacillus spp from Nigerian Traditional Condiments and Odeyele [25], who also isolated Bacillus spp from street food.

The microscopic results obtained from all species of Bacillus showed that they were gram positive and rod in shape. This agrees with the findings of Okonlawon [24], who detected Bacillus spp such as Bacillus cereus, Bacillus subtilis, Bacillus pumilus and Bacillus licheniformis from four Nigerian condiments (Iru, Dawadawa, Ogiri and Okpehe) as all these species were found to be gram positive rods and motile.

The biochemical characteristics of the Bacillus spp isolated in this work were confirmed [27]. Bacillus spp isolated in this work include, Bacillus cereus, Bacillus subtilis and Bacillus licheniformis and Bacillus cereus were found to be catalase positive, citrate positive, indole negative, lecithinase production positive, nitrate reduction positive, motility positive, methyl red negative and voges proskauer positive. These results are in agreement with the results of the study by Kotiranta [16], Ouoba [28] and Catia [3].

The occurrence of Bacillus cereus in this study showed that most of the samples examined were contaminated with Bacillus cereus having 51 (34\%), occurrence followed by Bacillus subtilis having $22(14.7 \%)$ and Bacillus licheniformis having $13(8.7 \%)$ occurrence, which as a result, revealed a high incidence of Bacillus cereus. This agrees with the findings of Okonlawon [24], who isolated Bacillus spp from four different local condiments (Iru, Dawadawa, Ogiri and Okpehe). The isolates were identified as Bacillus cereus, Bacillus subtilis, Bacillus pumilus and Bacillus licheniformis, where Bacillus cereus had the highest occurrence of 13 (38.24\%) followed by Bacillus subtilis 12 (35.30\%), Bacillus pumilus $4(11.76 \%)$ and Bacillus licheniformis $5(4.70 \%)$. The results of this research are also in agreement with the results of Ugwu [36], who also detected Bacillus cereus from rice, meat and fish samples. Bacillus cereus occurred in 123 (35.14\%) of rice samples, $111(31.71 \%)$ of meat samples and 116 (33.14\%) of fish samples. Ugwu [36] reported that, the presence of Bacillus cereus in food and food products could be as a result of the ubiguity of its spores to survive dried storage which means that most raw and ready to eat foods may contain Bacillus cereus. Odeyele [25] equally isolated Bacillus spp from street food which include Bacillus cereus, Bacillus subtilis, Bacillus licheniformis and Bacillus firmus. Bacillus cereus was found to occur in $84(56 \%)$ samples, Bacillus subtilis occurred in 36 (24\%), Bacillus firmus and Bacillus licheniformis equally occurred in $15(10 \%)$ samples. Bacillus cereus spores occur widely in foods and all kinds of foods have been implicated in Bacillus cereus food poisoning [9, 14].

The occurrence of Bacillus cereus in higher proportion than other species in awara samples may be due to the fact that Bacillus cereus is more adaptable to a wider varying environment than other species. The high incidence of Bacillus cereus in this study could be explained by the ubiguitous distribution of this organism and its ability to form endospores $[16,21]$ coupled with poor storage 
conditions, the unsanitary and largely unhygienic nature of the food preparations and services areas as foods are good indicators of the state of environment in which they are prepared or served $[8,26]$.

Molecular identification of Bacillus cereus enterotoxin genes by PCR revealed that, Bacillus cereus possessed the gene encoding the hblD enterotoxins and were detected among the Bacillus cereus isolates and a product size of 829 base pair was obtained. This corresponds with the work of Guinebretiere [12], who detected Bacillus cereus hblD enterotoxin gene from food and obtained a product size of 829 base pair.

This also agrees with the work of Basil [2], who also isolated Bacillus cereus from milk and milk products and were tested for the hblD enterotoxin genes in 11 isolates and found out that $90.9 \%$ possessed the hblD genes. These results are also in line with the work of Fayaz [10], who detected Bacillus cereus from meat and detected the hblD genes. About 28 isolates possessed one or more genes of hbl complex with an overall incidence of $63.63 \%$ of this complex. Montanhini [22], also isolated Bacillus cereus from dairy products and found out that Bacillus cereus strains incubated at $30^{\circ} \mathrm{C}$ produced the hbl enterotoxin. Same results were reported by Dufrenne [7], whose study found out that $100 \%$ of psychrotrophic Bacillus cereus strains produced the $\mathrm{hbl}$ enterotoxin. Therefore, this contamination is recognized to be a harzard to consumers. Lopez and Alippi [18], also worked on Bacillus cereus from food and reported that out of 132 Bacillus cereus isolates, all the four hbl genes (ABCandD) were detected in 55 strains (42\%). According to Lindback and Granum [19], about $40 \%$ of Bacillus cereus strains harbor the hblACD genes responsible for the hbl codification. For this reason, these enterotoxins protiens are considered to be the most important produced by these microorganisms.

The effective use of quality control and safety measures during production/manufacture besides creating awareness among food handlers and consumers becomes necessary to ward off the menace of Bacillus cereus and other food poisoning organisms [10].

The results of antibiotic susceptibility of the isolates showed that the susceptibility was determined by disc agar diffusion method. The enterotoxigenic $B$. cereus were susceptible to Pefloxacin, Ciprofloxacin, Streptomycin, Septrin and Erythromycin. Resistance was observed against Ampiclox, while Gentamycin, Zinnacef, Amoxacilin and Rocephin were observed to be less susceptible.

The findings of this study correspond with those obtained by other researchers [35]. The previous work have shown that antimicrobial susceptibility of Bacillus cereus were highly susceptible to Streptomycin, Chloramphenicol, Erythromycin, Ciprofloxacin and less susceptible to Ampicillin and Ampiclox [35].

This also agrees with the findings of Agwa [1], who reported that Bacillus cereus were highly resistance to Ampiclox and sensitive to Erythromycin, Chloramphenicol, Streptomycin and Ciprofloxacin and less sensitive to
Gentamycin [1]. Odeyele [25], also reported that all enterotoxigenic Bacillus cereus isolates were susceptible to Gentamycin and almost all to Ciprofloxacin, while Ampicillin, chloramphenicol and erythromycin showed resistance.

Turnbull [32] worked on 67 Bacillus cereus strains implicated in non-gastrointestinal infections and food poisoning and from the environment, reported that resistance to Ampicillin is constant while susceptibility to Erythromycin, Chloramphenicol is usually observed and also, susceptibility to Ciprofloxacin was uniform and it has been shown to be highly effective in the treatment of Bacillus cereus wound infections [32]. Weber [37] conducted studies on 54 Bacillus cereus strains isolated from blood cultures and showed that all strains tested were susceptible to Chloramphenicol, Gentamycin and Ciprofloxacin and many strains were susceptible to Erythromycin. Luna [20] also tested 42 Bacillus cereus isolates and reported results similar to those reported by Turnbull [32] and Weber [37]

In variance to my findings in final analysis of each of the reported studies of Turnbull [32], Weber [37] and Luna [20], small populations of Bacillus cereus isolates showed resistance to Erythromycin.

Variations in the zone of inhibition may be due to the differences in the concentrations of antimicrobial agents used, drug resistance transfer and the overall wide spread use of the antibiotics in the environment. The development of drug resistance may be due to the use of these drugs in the medical and veterinary practice to treat infections and misuse of the drugs resistance strains [1].

The multiple antibiotic resistances (MAR) index in this study is 0.1 . MAR index gives an indirect suggestion of the probable source of the organism and MAR index greater than 0.2 indicates that the organism must have originated from an environment where there are no strict rules concerning prescriptions and usage of antibiotics [29, 33].

The antimicrobial resistance patterns of Bacillus cereus from foods is useful in epidemiological studies [17] as it provides adequate awareness about the safety of consumable foods contaminated with high level of potential microbes for food borne disease outbreak, resulting to a distribution that cannot be controlled and thus bringing about changes in public health and deterioration thereby increasing susceptibility rate [31].

\section{Conclusions}

This research succeeded in isolating three species of Bacillus which include Bacillus cereus, Bacillus subtilis, and Bacillus licheniformis from "awara" samples in Kaduna metropolis using the mannitol egg yolk polymycin agar. All of them were gram positive rods, motile and spore formers. This research found that 51 (34\%) of 150 of the Bacillus strains isolated from "awara" samples in kaduna metropolis belonged to $B$. cereus while $B$. subtilis, B. licheniformis were found in $22(14.7 \%)$, and $13(8.7 \%)$ respectively. These food samples are highly contaminated with $B$. cereus, as its spores 
will not be eliminated from food materials by heat treatment. This research has also attempted to establish that potentiality of isolates of $B$. cereus, generally referred to as opportunistic foodborne pathogen, did harbour toxigenic traits as evidence by molecular studies where the isolate of Bacillus cereus possess the enterotoxin. The enterotoxic Bacillus cereus isolates were found to be susceptible to Pefloxacin, Ciprofloxacin, Streptomycin, Septrin and Erythromycin. Resistance was observed against Ampiclox while Gentamycin Zinnacef, Amoxacillin and Rocephin were found to be less susceptible. Based on the result of this research, the effective antibiotics against enterotoxigenic $B$. cereus strains isolated from "awara" in Kaduna metropolis are Pefloxacin, Ciprofloxacin, Steptomycin, Septrin and Erythromycin.

\section{References}

[1] Agwa, O. K., Uzoigwe, C. I. and Wokoma, E. C. (2012). Incidence and antibiotic sensitivity of Bacillius cereus isolated from ready to eat foods sold in some markets in Portharcourt, Rivers State, Nigeria. Asian journal of microbiology. Biotechnology and environmental science, 14 (1): 13-18.

[2] Basil A., Abbas Mohammed H. Khudor and Ban M. S. Saeed (2014). Detection of hbl, nhe, and bceT toxin genes in Bacillus cereus isolates by multiplex PCR. Int. journal of current microbiology and applied sciences ISSN: 2319-7706 vol 3 no. 11 (2014) Pp. 1009-1016.

[3] Catia, A. C. M., Martins, O. B., Clementino, M. M. (2008). Species-level identification of Bacillus Strains isolates from marine sediments by conventional biochemical, 16S rRNA gene sequencing and inter-tRNA gene sequence lengths analysis. Antonie van Leeuwenhoek 93:297-304.

[4] Claire Jenkins, Claire L. Ling, Holly L. Ciesielezuk, Julianne Lockwood, Susan Hopkins, Timothy D. McHugh, Stephen H. Gillespie and Christopher C. Kibbler. (2012). Detection and identification of bacteria in clinical samples by $16 \mathrm{SrRNA}$ gene sequencing: Comparism of two different approaches in clinical practice. Journal of Medical Microbiology. (2012), 61, 483-488 Doi 10.1099/jmm.0.030387-0.

[5] Cheesbrough, M. (2006). District Laboratory Practice in Tropical Countries. Cambridge University Press p. 434.

[6] CLSI. (2012). Performance standards for Antimicrobial Susceptibility Testing; Twenty-Second Informational Supplement. CLSI document M100-S22. Wayne, PA: Clinical and Laboratory Standards Institute; 2012.

[7] Dufrenne, J., Bijwaard, M., te Giffel, M., Beumer, R. and Notermans, S. (1995). Characteristics of some psychrotrophic Bacillus cereus isolates. International Journal of Food Microbiology 27 (2-3): 175-183.

[8] Ehirim, J. E., Azubike, M. C, Ubbaonu, C. N., Anyanwu E. C., Ibe, K. M., Obonna, M. O. (2001). Critical control point of complementary food preparation and handling in eastern Nigeria. Bulletin of the world health organization, 79 (5), 423435 .

[9] EFSA (2005). The European Union Summary Report on Trends and Sources of Zoonoses, Zoonotic Agents and Food- borne Outbreaks in 2010. EFSA Journal, vol 10 (3), pp. 2597, http://www.efsa.europa.eu/en/efsajournal/pub/2597.htm.

[10] Fayaz S., Badroo G. A., Ajaz Ahmad, Rasool U., Mustapha R., and Mudasir Mir. (2017). molecular characterization of enterotoxigenic Bacillus cereus species isolated from meat using conventional PCR and multiplex PCR. Int. j. curr. Microbial. App. Sci. 6 (9): 324-328.

[11] Frankland, G. C., and P. F. Frankland. (1887). Studies on some new microorgansisms from air. Philosophical transactions of the Royal Society of London. Series B, biological sciences 173:257-287.

[12] Guinberetiere M. H., Veronique Broussolle and Christophe Nguyen-the. (2002). Journal of clinical microbiology, Aug 2002, p. 3053-3056.

[13] Griffiths, M. W. and Schraft, H. (2002). Bacillus cereus food poisoning. pp. 261-270. In Cliver, D. O. and Riemann, H. P. (Eds.). Foodborne Diseases, 2nd edition, Academic Press, SNew York, NY. Granum, P. E. 1994. Bacillus cereus and its toxins. J. Appl. Bacteriol. Symp. Suppl. 76:615-665.

[14] Helgaison E., Okstad O. A., Caugaut D. A., Johansen H. A., Fouet A., Mock M., Hegna I. and Kolsto A. B. (2000). Bacillus anthracis, Bacillus cereus, Bacillus thuringenesis one species on the basis of genetic evidence. Appl Environ. 2000 Jun; 66 (6):2627-30.

[15] Holbrook R. and Anderson J. M. (1980). Can. J. Microbiol., 26 (7) $753-759$.

[16] Kotiranta, A., Lounatmaa, K., Haapasalo, M. (2000). Microbes and infection, 2000-Elsevier. Epidemiology and pathogenesis of Bacillus cereus infection. Vol 2, issue 2, Pp 189-198. Feb, 2000. Institute of Dentistry, P. O Box 41, FIN00014, University of Helsinki, Helsinki, Finland.

[17] Kwaga J. K. P. and Adesiyun A. A. (1984). Antibiograms of Staphylococcus aureus from some ready to eat products. Journal of food protection. November 1984, vol 47, No. 11 Pp 865-867.

[18] Lopez A. C. and Alippi A. M. (2010). Enterotoxigenic gene profiles of Bacillus cereus and Bacillus megaterium isolates recovered from honey. Revista Argentina de microbiologia (2010) 42:216-225.

[19] Lindbäck, T. and Granum, P. E. (2013). Bacillus cereus. In Labbé, R. G. and García S. (Eds). Guide to Foodborne Pathogens, p. 75-81. West Sussex: John Wiley \& Sons.

[20] Luna, V. A., D. S. King, J. G. Gulledge, A. C. Cannons, P. T. Amuso, and J. Cattani. (2007). Susceptibility of Bacillus anthracis, Bacillus cereus, Bacillus mycoides, Bacillus pseudomycoides and Bacillus thuringiensis to 24 antimicrobials using Sensititre automated microbial dilution and Etest agar gradient diffusion methods. J. Antimicrob. Chemother. 60:555-567.

[21] McKillip J. L. (2000). Prevalence and expression of enterotoxins in B. cereus and other Bacillus spp., a literature review. Antonie Van Leeuwenhoek. 2000; 77 (4):393-399.

[22] Montanhini, M. T. M., Montanhini Neto, R. and Bersot, L. S. (2015). Enterotoxigenic potential of Bacillus cereus strains isolated from dairy products at different incubation temperatures. Int. food research journal 22 (3): 1315-1317 (2015). 
[23] Mohammad Shahriar, M. d. Rashidul Haque, Shaila Kabir, Irin Dewan and Mohiuddin Ahmed Bhuyiabn. (2011). Effect of Protinsae-k on Genomic DNA Extraction from Gram Positive Strains. Standard journal of pharmaceutical sciences 4 (1): 53-57.

[24] Okanlawon, B. M., Ogunbanwo, S. T., and okunlola, A. O. (2010). Growth of Bacillus cereus isolated from some traditional condiments under different regiments. Department of biomedical sciences, university of technology, Oyo state and department of botany and microbiology, university of Ibadan, Nigeria.

[25] Odeyele, O. P., Whong, C. M. Z., Jatau E. D. (2014). Characterization and antibiotic susceptibility pattern of Bacillus cereus isolates from fried soya bean cake in Zaria, Nigeria. Scientific journal of microbiology (2014). 3 (4) 3844.

[26] Omemu, A. M., and Aderoju, S. T. (2008). Food safety knowledge and practices of street food vendors in the city of Abeokuta, Nigeria. Food control, 19:396-402.

[27] Oyeleke, Solomom Bankole., and Manga, Bala Shuaibu. (2008). Essentials of laboratory practicals in microbiology, $1^{\text {st }}$ edition Pp. 20. ISBN NO: 978-2206-69-5.

[28] Ouoba, L. I. I., Parkouda, C., Diawara, C., Scotti, C., Varnam, A. H. (2007). Identification of Bacillus spp. from Bikalga, fermented seeds of Hibiscus sabdariffa: phenotypic and genotypic characterization. Journal of Applied Microbiology ISSN 1364-5072.

[29] Olayisnka, A. T, B. O. Olayinka and B. A. Onile (2004). Antibiotic susceptibility and plasmid pattern of pseudomonas aeruginosa from the surgical unit of a university teaching hospital in north central Nigeria. International journal of medicine and medical.

[30] Schraft, H. and Griffiths, M. W. (2006). Bacillus cereus gastroenteritis. pp. 561-582. In H. Riemann and D. O. Cliver (Eds). Foodborne Infections and Intoxications, 3rd ed, Academic Press, New York, NY.

[31] Sahota Parampal, Jairath S., Pandove Gulab and Krishan M. (2008). Emerging food borne pathogens-A review. Asian journal of microbiology and environmental sciences 10 (4): 921-926. January 2008.

[32] Turnbull, P. C. B., N. M. Sirianni, C. L. LeBron, M. N. Samaan, F. N. Sutton, A. E. Reyes, and L. F. Peruski Jr. (2004). MICs of selected antibiotics for Bacillus anthracis, Bacillus cereus, Bacillus thuringiensis, and Bacillus mycoides from a range of clinical and environmental sources as determined by Etest. J. Clin. Microbiol. 42:3626-3634.

[33] Tripathi R. Vinayak, Shailendra Kumar and Satyendra K. Garg. (2011). A study on trypsin, Aspergillus flavus and Bacillus spp. Protease inhibitory activity in Cassia tora (L.) Syn Senna tora (L.) Roxb. Seed extract. The official journal of the international society for complementary medicine research (ISCMP). 2011 11:56.

[34] Tallent, S. M, K. M. Kotewicz, E. A., Strain and R. W. Bennett. (2012). Efficient isolation and identification of Bacillus cereus group. Journal of AOAC international, 95 (2): 446-451.

[35] Umar, A. S., Yerima, M. B. and Uzal, U. (2006). Antimicrobial sensitivities of Bacillus cereus isolated from food samples sold in Bauchi metropolis to selected antibiotics. Nigerian Journal of Microbiology. 20 (1), 655-661.

[36] Ugwu, Celestina Chibuzo. (2009). Isolation and characterization of Bacillus cereus strains from various foods in Nsukka. Department of microbiology, university of Nigeria, Nsukka. March, 2009.

[37] Weber, D. J., S. M. Saviteer, W. A. Rutala, and C. A. Tomann. (1988). In vitro susceptibility of Bacillus spp. to selected antimicrobial agents. Antimicrob. Agents Chemother. 32:642645 .

[38] Wijnands L. M., Dufrenne J. B., Rombouts F. M., in 'T Veld P. H., and van Leusden F. M. (2006) Prevalence of potentially pathogenic Bacillus cereus in food commodities in the Netherlands. Journal of Food Protection 69 (11):2587-2594.

[39] Zhou J., Bruns M. A. and Tiedje J. M. (1996). DNA recovery from soils of diverse composition. Appl. Environ. Microbiol. 62: 316-322. 